\title{
Blood eosinophil level and lung function trajectories: cross-sectional and longitudinal studies in European cohorts
}

Ida Mogensen ${ }^{1,2}$, Judith M. Vonk $\mathbb{1}^{3,4}$, Sara R.A. Wijnant $\mathbb{1}^{5,6,7}$, Xingwu Zhou ${ }^{1,2}$, H. Marike Boezen ${ }^{3,4}$, Guy Brusselle $\mathbb{C}^{5,6,8}$, Lies Lahousse $\mathbb{1}^{6,7}$, Christer Janson (10) 2 and Andrei Malinovschi (i) ${ }^{1}$

\begin{abstract}
Affiliations: ${ }^{1}$ Dept of Medical Sciences, Clinical Physiology, Uppsala University, Uppsala, Sweden. ${ }^{2}$ Dept of Medical Sciences, Lung-, Allergy- and Sleep Research, Uppsala University, Uppsala, Sweden. ${ }^{3}$ Dept of Epidemiology, University of Groningen, University Medical Centre Groningen, Groningen, The Netherlands. ${ }^{4}$ Groningen Research Institute for Asthma and COPD (GRIAC), University of Groningen, University Medical Centre Groningen, Groningen, The Netherlands. ${ }^{5}$ Dept of Respiratory Medicine, Ghent University Hospital, Ghent, Belgium. ${ }^{6}$ Dept of Epidemiology, Erasmus Medical Centre, Rotterdam, The Netherlands. ${ }^{7}$ Dept of Bioanalysis, Faculty of Pharmaceutical Sciences, Ghent University, Ghent, Belgium. ${ }^{8}$ Dept of Respiratory Medicine, Erasmus Medical Centre, Rotterdam, The Netherlands.
\end{abstract}

Correspondence: Ida Mogensen, Akademiska sjukhuset, 75185 Uppsala, Sweden.

E-mail: ida.mogensenamedsci.uu.se

\section{ABSTRACT}

Background: Elevated blood eosinophils have been associated with lower lung function and are believed to be associated with accelerated lung function decline.

Method: Blood eosinophils were measured in four cohorts: <45 years cohort within the Vlagtwedde-Vlaardingen (V\&V) study, the Uppsala cohort of the European Community Respiratory Health Survey (ECRHS-Uppsala; $<45$ years), $\geqslant 45$ years cohort within the V\&V study, and the Rotterdam study ( $\geqslant 45$ years). Blood eosinophils at baseline were classified as normal $\left(<300\right.$ cells $\left.\mu \mathrm{L}^{-1}\right)$ or elevated $\left(\geqslant 300\right.$ cells $\left.\cdot \mu \mathrm{L}^{-1}\right)$. Lung function was measured at baseline and follow-up with spirometry: forced expiratory volume in $1 \mathrm{~s}\left(\mathrm{FEV}_{1}\right)$, vital capacity $(\mathrm{VC})$ and their ratio $\mathrm{FEV}_{1} / \mathrm{VC}$. The association between blood eosinophils and lung function was tested cross-sectionally using linear regression and longitudinally using a mixed model, both adjusted for age, sex, height, pack-years smoking and smoking status. Stratified analyses were done for asthma.

Results: Elevated blood eosinophils were associated with lower $\mathrm{FEV}_{1}$ (regression coefficient $-147 \mathrm{~mL}(95 \%$ $\mathrm{CI}-188$ to $-105 \mathrm{~mL}))$, $\mathrm{VC}(-120 \mathrm{~mL}(-165$ to $-75 \mathrm{~mL}))$ and $\mathrm{FEV}_{1} / \mathrm{VC}(-1.3 \%(-1.9 \%$ to $-0.6 \%))$ at baseline in the two $<45$ years cohorts, and with lower $\mathrm{FEV}_{1}(-70 \mathrm{~mL}(-112$ to $-27 \mathrm{~mL}))$ and $\mathrm{FEV}_{1} / \mathrm{VC}$ $(-1.8 \%(-2.6 \%$ to $-1.0 \%))$ in the two $\geqslant 45$ years cohorts. Elevated blood eosinophils were associated with an accelerated decline in $\mathrm{FEV}_{1}\left(-5.5 \mathrm{~mL} \cdot \mathrm{year}^{-1}\left(95 \% \mathrm{CI}-10.5\right.\right.$ to $\left.\left.-0.5 \mathrm{~mL} \cdot \mathrm{year}^{-1}\right)\right)$ and VC $\left(-6.4 \mathrm{~mL} \cdot \mathrm{year}^{-1}\right.$ $\left(-11.26\right.$ to $-1.5 \mathrm{~mL} \cdot$ year $\left.^{-1}\right)$ ) compared to normal blood eosinophils in the younger asthmatic subjects in the longitudinal studies.

Conclusion: Elevated blood eosinophils are associated with lower lung function in the general population and with an accelerated lung function decline among asthmatic individuals.

@ERSpublications

Elevated blood eosinophils ( $\geqslant 300$ cells per $\mu \mathrm{L}$ ) associate with lower lung function in an adult general population and with a worse lung function trajectory in adult asthmatic individuals https://bit.ly/3fJJ10h

Cite this article as: Mogensen I, Vonk JM, Wijnant SRA, et al. Blood eosinophil level and lung function trajectories: cross-sectional and longitudinal studies in European cohorts. ERJ Open Res 2020; 6: 00320-2020 [https://doi.org/10.1183/23120541.00320-2020].

This article has supplementary material available from openres.ersjournals.com

Received: 27 May 2020 | Accepted: 15 June 2020

Copyright $\odot$ ERS 2020. This article is open access and distributed under the terms of the Creative Commons Attribution Non-Commercial Licence 4.0 


\section{Introduction}

Lung function volumes increase in most subjects until around the age of 15-20 years and starts to decline around the age of 25 years [1]. An impaired peak lung function as well as an accelerated decline can contribute to low lung function at a later age $[2,3]$. A common cause of accelerated lung function decline is cigarette smoking, which can lead to chronic obstructive pulmonary disease (COPD) with persistently reduced forced expiratory volume in $1 \mathrm{~s}\left(\mathrm{FEV}_{1}\right)$ [4] and $\mathrm{FEV}_{1}$ /forced vital capacity (FVC) ratio [5]. Accelerated lung function decline is also observed in some asthmatic individuals and has been related to airway remodelling, with basal membrane thickening, excess mucus production, airway smooth muscle hyperplasia and epithelial shedding [6], ultimately leading to fixed airflow obstruction with persistently reduced $\mathrm{FEV}_{1}$ and $\mathrm{FEV}_{1} / \mathrm{FVC}$ ratio. In $\mathrm{COPD}$, the mechanisms associated with accelerated lung function decline are probably different from those in asthma and associated to a lesser extent with eosinophil inflammation [7].

In asthma and COPD, eosinophilic airway inflammation is seen as a specific phenotype with elevated levels of sputum eosinophils and/or blood eosinophils affecting one-third [8,9] to half of the patients [10]. Blood eosinophils are associated with sputum eosinophils [11, 12]. Anti-interleukin (IL)-5 therapies, which almost deplete blood eosinophil levels, reduce exacerbations in patients with severe refractory asthma with high levels of blood eosinophils [13].

In previous population-based investigations, elevated blood eosinophils have been found to be associated with lower lung function in the general population [14-16]. In asthmatic populations, elevated blood eosinophils are likewise associated with lower $\mathrm{FEV}_{1}$, especially when both local and systemic eosinophil inflammation is present $[10,17]$. Over time, some studies have found that a higher blood eosinophil level is associated with an accelerated lung function decline in the general population $[14,18]$ and a lower maximally attained lung function [1]; however, this finding is not consistent across studies [19]. Also in studies among asthmatic subjects, the associations between blood eosinophil levels and lung function development have been diverse [18-22]. Hence, it is still unclear whether eosinophilic inflammation is a driving factor in lung function decline, and whether this association is specific or not for persons with asthma.

Therefore, we analysed the relation between blood eosinophils and lung function level and decline in four different population-based cohorts. The cohorts were followed during different decades (from the 1950s to 2010s) both before and after introduction of inhaled corticosteroids (ICS) and with a wide age span to identify patterns of lung function impairment. Our hypothesis was that elevated blood eosinophils are associated with a lower lung function level (cross-sectional analysis) and with an accelerated lung function decline during the follow-up time (longitudinal analysis). Moreover, we stratified our analyses according to the presence or absence of asthma to see whether it was a common cause of both the accelerated lung function decline and higher blood eosinophil levels.

\section{Material and methods}

\section{Populations}

The Vlagtwedde-Vlaardingen study, which began in 1965, took its study population from the two communities of Vlagtwedde and Vlaardingen in the Netherlands and involved $>8000$ participants [23, 24]. The study followed up the participants approximately every 3 years, with the maximum number of visits per participant being eight (at most 25 years of follow-up data). In total, 6684 participants were included in the cross-sectional analysis, and 3642 were included in the longitudinal analysis (subjects had at least two spirometry measurements over a period of at least 5 years). The study population was divided into two separate cohorts, based on their age at baseline: 18-44 years (<45 years) versus $45-74$ years $(\geqslant 45$ years $)$.

The European Community Respiratory Health Survey (ECRHS) is a multinational European cohort with three visits: 1991-1992, 1999-2000 and 2011-2012. In this study, eligible participants from the study centre in Uppsala, Sweden (ECRHS-Uppsala) were included. They were randomly selected and aged 20-44 years, and were included for a questionnaire in 1990. A random sample of 800 subjects was selected for clinical examination during 1991-1992, and in addition to them, the subjects who had reported asthma symptoms in the initial questionnaire [25]. In total, 836 subjects were examined, 676 of whom performed a spirometry test and had blood eosinophils measured at baseline. Of these 676 individuals, 487 subjects participated in at least one of the two follow-ups.

The Rotterdam study is a population-based cohort study that started in 1989 comprising almost 20000 participants aged $\geqslant 45$ years, which aimed to assess the occurrence of, and risk factors for, chronic diseases in the elderly [26]. Every 3-4 years, participants underwent a home interview and clinical examinations at the research centre. The current study contains participants who visited the Rotterdam research centre 
between 2014 and 2016 (RS-I-6 and RS-II-4) and had an interpretable spirometry and a measured blood eosinophil count. This population was aged 70-95 years at this follow-up. At that time, 2857 participants were invited for examination, 1737 of whom were eligible (figure 1).

In all cohorts, smoking status and smoking history were self-reported, and the number of pack-years (one pack-year corresponding to one pack of 20 cigarettes smoked daily during 1 year) was calculated. Smoking status was divided into never-, ex- or current smokers.

In the Vlagtwedde-Vlaardingen study, asthma was defined as present when the participant answered yes to the question "Have you ever had attacks of shortness of breath with wheezing at rest?" In the ECRHS-Uppsala, current asthma at baseline was defined as present if the subject self-reported a doctor's diagnosis of asthma, used asthma medication and/or had an asthma attack in the past 12 months. In the Rotterdam study, current asthma was defined as asthma diagnosis by a doctor and asthma symptoms and/ or medication in the last 6 months [27].

No information on medication was available in the Vlagtwedde-Vlaardingen study. In the ECRHS-Uppsala, ICS use or oral corticosteroid (OCS) use was reported for the past 12 months. In the Rotterdam study, medication prescription data were available through automated pharmacy records. ICS or OCS use was defined as presence of a prescription within 90 days prior to the date of blood analysis.

\section{Lung function}

Pre-bronchodilation values were used for all analyses. In the Vlagtwedde-Vlaardingen study, a water-sealed spirometer (Lode Spirograph D52, Lode, Groningen, the Netherlands) was used [1]. In the ECRHS-Uppsala, a dry rolling seal spirometer system (Sensor Medics 2130, Sensor Medics, Anaheim, CA, USA) was used in the first and second survey, while the NDD Easy One spirometer (NDD Medizintechnik, Zurich, Switzerland) was used in the third survey. In the Rotterdam study, a Master

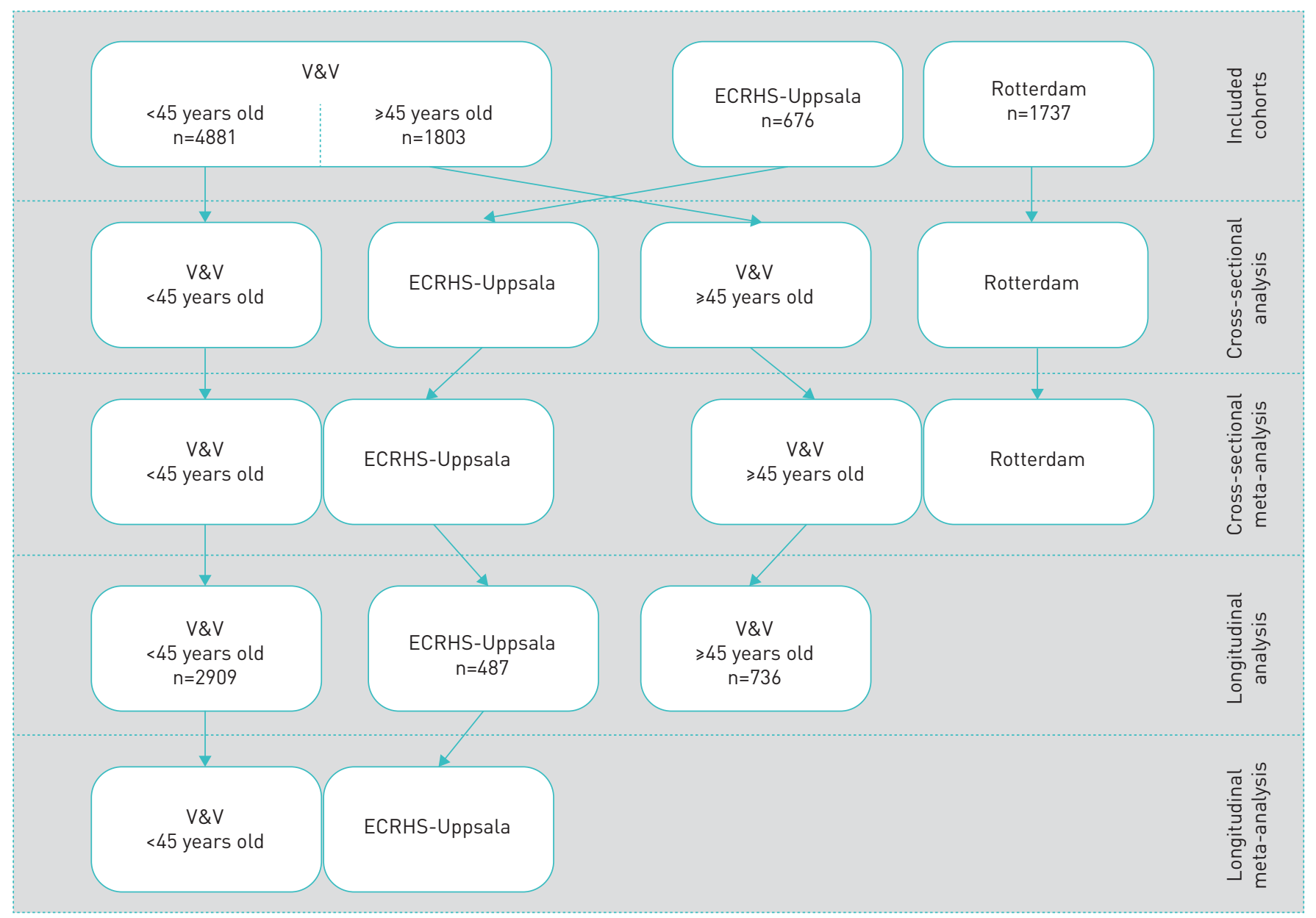

FIGURE 1 Study model. V\&V: Vlagtwedde-Vlaardingen; ECRHS: European Community Respiratory Health Survey. 
Screen PFT Pro (Care Fusion Netherlands, Houten, the Netherlands) was used. In the Vlagtwedde-Vlaardingen study, the $\mathrm{FEV}_{1}$ and inspiratory vital capacity (IVC) was measured and $\mathrm{FEV}_{1} /$ IVC was calculated at all visits. In the ECRHS-Uppsala and Rotterdam studies, FVC was measured. The term "VC" in the paper refers to IVC in the Vlagtwedde-Vlaardingen study and FVC in the ECRHS or Rotterdam studies. Predicted $\mathrm{FEV}_{1}$ and FVC values were calculated using the Global Lung Initiative reference equations [28]. In all cohorts, spirometry was conducted according to the American Thoracic Society/European Respiratory Society guidelines present at the time of examination.

\section{Blood eosinophils}

In the Vlagtwedde-Vlaardingen study, blood eosinophil counts were assessed at baseline in a 1:11 dilution of peripheral blood with a Bürker counting chamber [29]. In the ECRHS, blood eosinophils were analysed at baseline on a Hemalog 2R (Technicon Chemicals Company, Tournai, Belgium), in $5 \mathrm{~mL}$ blood supplemented with EDTA $\left(0.34 \mathrm{~mol} \cdot \mathrm{L}^{-1}\right)$ [25]. In the Rotterdam study, blood eosinophils were measured with a Sysmex XS-800 Hematology analyser (Sysmex, Norderstedt, Germany) in blood supplemented with EDTA. Blood eosinophils were analysed dichotomised (elevated if $\geqslant 300$ cells $\mu \mathrm{L}^{-1}$ or normal if $<300$ cells $\left.\mu \mathrm{L}^{-1}[30]\right)$.

\section{Statistical methods}

Cross-sectional analyses

The four cohorts were cross-sectionally analysed separately in multivariate linear regression analyses with elevated blood eosinophils compared to normal blood eosinophils as the independent variable and $\mathrm{FEV}_{1}$, $\mathrm{VC}$ and $\mathrm{FEV}_{1} / \mathrm{VC}$ as outcomes. Inverse variance weighted meta-analyses were conducted on results from the $<45$ years Vlagtwedde-Vlaardingen cohort and the ECRHS-Uppsala cohort, and from the $\geqslant 45$ years Vlagtwedde-Vlaardingen cohort and the Rotterdam cohort. The analyses were adjusted for age, sex, height, weight, smoking and pack-years of cigarette smoking.

\section{Longitudinal analyses}

The longitudinal analyses were performed with mixed models, having elevated blood eosinophils as an independent variable and lung function decline over time, in $\mathrm{mL}$ per year $\left(\mathrm{FEV}_{1}\right.$ and $\left.\mathrm{VC}\right)$ and change in percent $\mathrm{FEV}_{1} / \mathrm{VC}$ per year as outcome. Results from the $<45$ years Vlagtwedde-Vlaardingen cohort and ECRHS-Uppsala cohort were further meta-analysed using an inverse variance weighted meta-analysis. Analyses were adjusted for age, sex, height, weight, smoking and pack-years of cigarette smoking. In the Rotterdam study, blood eosinophils were measured at the most recent study visit, and this cohort was not longitudinally analysed.

\section{Asthma}

To evaluate effect modification by asthma, known to be associated with higher blood eosinophils and potentially related to an accelerated lung function decline, asthma-stratified regression analyses were performed both cross-sectionally and longitudinally.

\section{Sensitivity analyses}

Analyses for the association between blood eosinophils as a continuous variable (logarithmised) and lung function were performed both cross-sectionally and longitudinally to evaluate the association, independent of the chosen blood eosinophil cut-off. Also, analyses with additional adjustments for OCS and ICS use in the ECRHS-Uppsala and Rotterdam cohorts were performed to evaluate the potential confounding effect of steroid treatment on the association between blood eosinophils and lung function.

The statistical analyses in the Vlagtwedde-Vlaardingen study were done in SPSS version 23 (released 2015; IBM SPSS Statistics for Windows, Version 23.0; IBM Corp., Armonk, NY, USA) and in the ECRHS-Uppsala study in Stata/IC 15.1 (StataCorp, College Station, TX, USA). The analyses in the Rotterdam study and the meta-analyses were done in $\mathrm{R}$ version 3.6.1 ( $\mathrm{R}$ Foundation for Statistical Computing, Vienna, Austria).

\section{Ethics}

The Vlagtwedde-Vlaardingen study protocol was approved by the Medical Ethics Committee of the University Medical Centre Groningen, Groningen, The Netherlands. All participants provided informed written consent.

ECRHS-Uppsala was approved by the Regional Ethical Review Board in Uppsala, Sweden (Dnr. 1991/33; 1999/313; 2010/068), and all participants signed the informed consent. 
The Rotterdam study was approved by the institutional review board (Medical Ethics Committee) of the Erasmus Medical Centre and by the review board of The Netherlands Ministry of Health, Welfare and Sports (Dnr. MEC 02.115).

\section{Results}

The baseline characteristics of the four cohorts are shown in table 1. The blood eosinophil level was lowest in the Vlagtwedde-Vlaardingen study and highest in the Rotterdam study. The $\mathrm{FEV}_{1}$ (\% pred) was close to $100 \%$ at baseline in the ECRHS and Rotterdam studies; $86 \%$ in the $<45$ years Vlagtwedde-Vlaardingen cohort and $80 \%$ in the $\geqslant 45$ years Vlagtwedde-Vlaardingen cohort. The mean age was highest in the Rotterdam study (78 years). The Vlagtwedde-Vlaardingen $<45$ years cohort had the highest prevalence of current smokers, while the ECRHS-Uppsala and $\geqslant 45$ years Vlagtwedde-Vlaardingen cohort had the highest prevalence of never-smokers (50\%). The prevalence of asthma was highest in the ECRHS cohort, which was enriched with asthmatic subjects, at $13 \%$, and lowest in the Vlagtwedde-Vlaardingen cohorts at $3-4 \%$ (table 1). The Rotterdam study had $7.7 \%$ asthmatic participants. The use of ICS among the asthmatic individuals was $33 \%$ in the ECRHS study and $49 \%$ in the Rotterdam study. The baseline characteristics stratified on asthma are presented in supplementary table S1a and b, and of the subjects included in the longitudinal analysis in supplementary table S2.

\section{Cross-sectional analysis}

In the cross-sectional analysis, elevated blood eosinophils were associated with a lower $\mathrm{FEV}_{1}$ in all cohorts, with borderline statistical significance $(\mathrm{p}=0.057)$ in the Rotterdam study (table 2) and a significant association in the meta-analyses (figure 2). Moreover, elevated blood eosinophils were associated with a lower $\mathrm{VC}$ in the $<45$ years cohorts but not in the $\geqslant 45$ years cohorts. Elevated blood eosinophils were associated with a lower $\mathrm{FEV}_{1} / \mathrm{VC}$ in all cohorts (table 2) and this was also seen in the meta-analyses (figure 2). Stratified for asthma, the $<45$ years Vlagtwedde-Vlaardingen cohort showed an association between elevated blood eosinophils, compared to normal blood eosinophils, and a lower lung function, in both asthmatic and non-asthmatic individuals, but with larger estimates among asthmatic individuals. In the ECRHS-Uppsala, there was a significant association between elevated blood eosinophils compared to normal blood eosinophils and lower lung function only among the non-asthmatic individuals. In the $\geqslant 45$ years cohorts, there were associations between elevated blood eosinophils and lower VC among the asthmatic patients from Vlagtwedde-Vlaardingen, and a lower ratio among the non-asthmatic individuals from Vlagtwedde-Vlaardingen and a trend in Rotterdam (table 3). In the meta-analyses elevated blood eosinophils in general were associated with lower lung function estimates in the asthma group; however, the smaller group size yielded larger confidence intervals (figure 2).

\section{TABLE 1 Characteristics of the cross-sectional study populations}

\begin{tabular}{|c|c|c|c|c|}
\hline & $\begin{array}{c}\text { V\&V } \\
18-44 \text { years of age }\end{array}$ & $\begin{array}{l}\text { ECRHS-Uppsala } \\
20-45 \text { years of age }\end{array}$ & $\begin{array}{c}\text { V\&V } \\
45-74 \text { years of age }\end{array}$ & $\begin{array}{c}\text { Rotterdam } \\
70-95 \text { years of age }\end{array}$ \\
\hline Subjects & 4881 & 676 & 1803 & 1737 \\
\hline Age years & $30.3 \pm 8.0$ & $33 \pm 7.3$ & $53 \pm 5.9$ & $78 \pm 5.1$ \\
\hline Never-smokers & $1559(32 \%)$ & $338(50 \%)$ & $896(50 \%)$ & $589(34 \%)$ \\
\hline Previous smokers & $490(10 \%)$ & $154(23 \%)$ & $146(8 \%)$ & $1036(60 \%)$ \\
\hline Asthma & $176(3 \%)$ & $90(13 \%)$ & $65(3.6 \%)$ & $127(7.5 \%)$ \\
\hline ICS use & & $38(6 \%)$ & & $155(9 \%)$ \\
\hline ICS use, asthmatic individuals & & $30(33 \%)$ & & $79(48 \%)$ \\
\hline OCS use & & $2(0.3 \%)$ & & $123(7 \%)$ \\
\hline OCS use, asthmatic individuals & & $2(2 \%)$ & & $26(16 \%)$ \\
\hline BMI $\mathbf{k g} \cdot \mathrm{m}^{-2}$ & $24.6 \pm 3.5$ & $23.3 \pm 3.5$ & $27.4 \pm 4.0$ & $27.4 \pm 4.1$ \\
\hline
\end{tabular}


TABLE 2 Associations between elevated blood eosinophils $\left(\geqslant 300\right.$ cells $\left.\cdot \mu \mathrm{L}^{-1}\right)$ and lung function in a cross-sectional analysis

\begin{tabular}{|c|c|c|c|}
\hline & $\begin{array}{c}\mathrm{FEV}_{1}{ }^{\#} \mathrm{~mL} \\
\beta(95 \% \mathrm{CI})\end{array}$ & $\begin{array}{l}V^{\#, 9} \mathrm{~mL} \\
\beta(95 \% \mathrm{CI})\end{array}$ & $\begin{array}{l}\mathrm{FEV}_{1} / \mathrm{VC}^{\#, \uparrow} \% \\
\beta(95 \% \mathrm{CI})\end{array}$ \\
\hline Vlagtwedde-Vlaardingen $<45$ years of age, $n=4881$ & $-142(-188$ to -96$)$ & $-120(-169$ to -71$)$ & $-1.1(-1.9$ to -0.3$)$ \\
\hline Vlagtwedde-Vlaardingen $\geqslant 45$ years of age, $n=2139$ & $-108(-184$ to -32$)$ & $-40(-119$ to 39$)$ & $-2.9(-4.4$ to -1.5$)$ \\
\hline Rotterdam, $n=1686$ & $-52(-104$ to 0.4$)$ & $-12(-73$ to 50$)$ & $-1.3(-2.3$ to -0.4$)$ \\
\hline
\end{tabular}

Significant associations in bold. $\mathrm{FEV}_{1}$ : forced expiratory volume in $1 \mathrm{~s}$; VC: vital capacity; $\beta$ : regression coefficient; $\mathrm{Cl}$ : confidence interval; ECRHS: European Community Respiratory Health Survey. ": adjusted for previous or current smoking, pack-years, age, sex, height and weight; ๆ: forced VC in the Rotterdam and ECRHS studies, or inspiratory VC in the Vlagtwedde-Vlaardingen study.

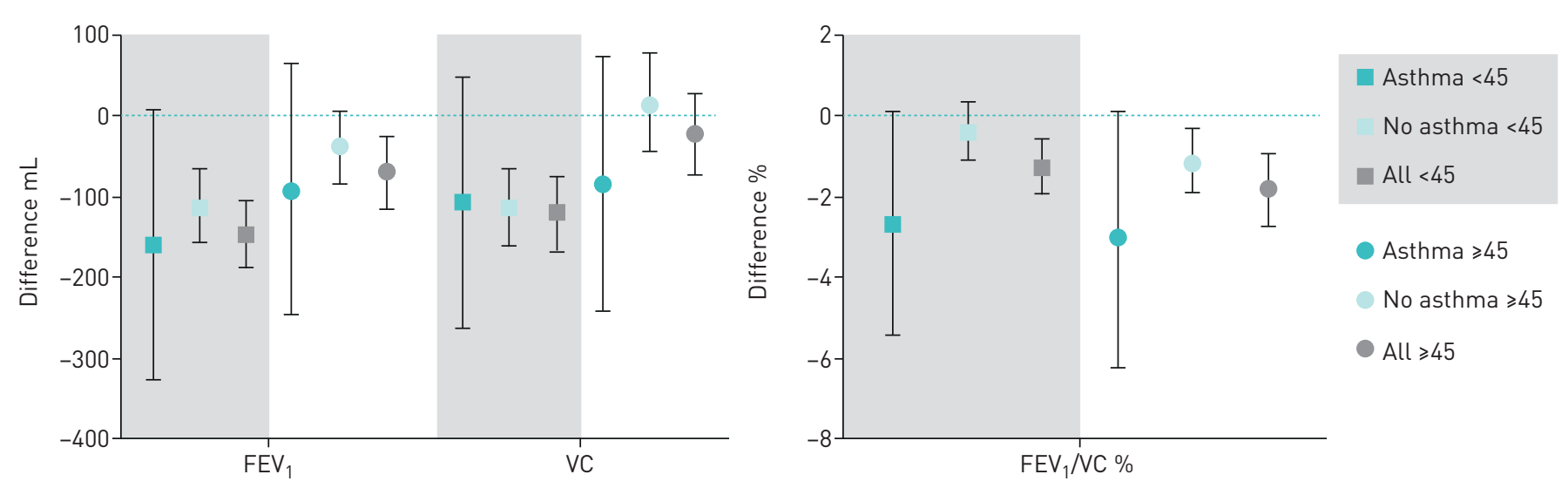

\begin{abstract}
Longitudinal analysis
In the longitudinal analysis, no statistically significant associations were seen between elevated blood eosinophils at baseline and an accelerated lung function decline in the two Vlagtwedde-Vlaardingen cohorts or in the meta-analyses (figure 3). In the ECRHS-Uppsala, elevated blood eosinophils were associated with an accelerated $\mathrm{FEV}_{1}$ and $\mathrm{VC}$ decline, while $\mathrm{FEV}_{1} / \mathrm{VC}$ was not significantly affected (table 4). Stratified for asthma, elevated compared to normal blood eosinophils at baseline was associated with an accelerated VC decline among asthmatic individuals in the $<45$ years Vlagtwedde-Vlaardingen cohort, and with an accelerated $\mathrm{FEV}_{1}$ decline among asthmatic individuals and an accelerated $\mathrm{VC}$ decline among the non-asthmatic individuals in the ECRHS-Uppsala cohort (table 5). The $\geqslant 45$ years Vlagtwedde-Vlaardingen cohort had too few asthmatic subjects to analyse $(n=19)$. In the meta-analyses, an accelerated decline in $\mathrm{FEV}_{1}$ and $\mathrm{VC}$ was seen among the asthmatic individuals, but not the non-asthmatic individuals (figure 3).
\end{abstract}

\title{
Sensitivity analyses
}

There were only minor differences when blood eosinophils were analysed as a continuous variable in the cross-sectional (supplementary table S3) and longitudinal analyses (supplementary table S4). In the ECRHS-Uppsala, adjustment for ICS/OCS resulted in a non-significant association between elevated blood eosinophils and a lower $\mathrm{VC}$ and $\mathrm{FEV}_{1} / \mathrm{VC}$ in the cross-sectional analysis and a non-significant association with accelerated VC decline among non-asthmatic individuals in the longitudinal analysis. The association between elevated blood eosinophils and lower $\mathrm{FEV}_{1}$ became significant $(-45 \mathrm{~mL}, 95 \% \mathrm{CI}-82$ to $-8 \mathrm{~mL})$ among the non-asthmatic individuals with adjustment for ICS/OCS in the Rotterdam study.

\section{Discussion}

In this study, we investigated the association between elevated blood eosinophils (i.e. $\geqslant 300$ cells $\mu \mathrm{L}^{-1}$ ) and lung function parameters in cross-sectional and longitudinal analyses in four European cohorts. The main results show an association between elevated blood eosinophils and lower lung function cross-sectionally in the entire population. Longitudinally, the results were more scattered. Meta-analysed, an association between elevated blood eosinophils and an accelerated $\mathrm{FEV}_{1}$ and $\mathrm{VC}$ decline was found in asthmatic

FIGURE 2 Cross-sectional meta-analyses, presenting results for the whole cohort and stratified for asthma. Grey-shaded areas represent the meta-estimates and $95 \%$ confidence intervals for the two $<45$ years cohorts. FEV 1 : forced expiratory volume in $1 \mathrm{~s}$; VC: vital capacity (forced VC in the Rotterdam and European Community Respiratory Health Survey studies, or inspiratory VC in the Vlagtwedde-Vlaardingen study). 
TABLE 3 Asthma-stratified analysis, cross-sectional associations between elevated blood eosinophils $\left(\geqslant 300\right.$ cells· $\left.\mu L^{-1}\right)$ and lung function

\begin{tabular}{|c|c|c|c|}
\hline & $\begin{array}{l}\text { FEV }_{1} \text { adjusted }^{\#} \mathrm{~mL} \\
\quad \text { ( }(95 \% \mathrm{CI})\end{array}$ & $\begin{array}{c}\text { VC adjusted }{ }^{\# \Uparrow} \mathrm{mL} \\
\beta(95 \% \mathrm{CI})\end{array}$ & $\begin{array}{c}\text { FEV }_{1} / \mathrm{VC} \text { adjusted } \\
\beta(19 \% \% \mathrm{CI})\end{array}$ \\
\hline $\begin{array}{l}\text { Asthma } \\
\text { Vlagtwedde-Vlaardingen }<45 \text { years of age, } n=176\end{array}$ & $-385(-610$ to -159$)$ & $-215(-414$ to -16$)$ & $-6.1(-10.3$ to -1.8$)$ \\
\hline $\begin{array}{l}\text { No asthma } \\
\text { Vlagtwedde-Vlaardingen }<45 \text { years of age, } n=4703\end{array}$ & $-102(-150$ to -55$)$ & $-106(-158$ to -55$)$ & $-0.3(-1.1$ to 0.6$)$ \\
\hline $\begin{array}{l}\text { Asthma } \\
\text { ECRHS-Uppsala, } n=90\end{array}$ & $125(-129$ to 381$)$ & $67(-187$ to 321$)$ & $-0.12(-3.8$ to 3.6$)$ \\
\hline $\begin{array}{l}\text { Asthma } \\
\text { Vlagtwedde-Vlaardingen } \geqslant 45 \text { years of age, } n=65\end{array}$ & $-309(-687$ to 69$)$ & $-382(-663$ to -102$)$ & $-5.2(-14.1$ to 3.7$)$ \\
\hline $\begin{array}{l}\text { No asthma } \\
\quad \text { Vlagtwedde-Vlaardingen } \geqslant 45 \text { years of age, } n=1738\end{array}$ & $-53(-131$ to 25$)$ & $111(-32$ to 254$)$ & $-1.8(-3.2$ to -0.3$)$ \\
\hline $\begin{array}{l}\text { Asthma } \\
\quad \text { Rotterdam, } n=127\end{array}$ & $-44(-217$ to 128$)$ & $64(-131$ to 260$)$ & $-2.7(-6.1$ to 0.7$)$ \\
\hline
\end{tabular}

Significant associations in bold. $\mathrm{FEV}_{1}$ : forced expiratory volume in $1 \mathrm{~s}$; VC: vital capacity; $\beta$ : regression coefficient; $\mathrm{Cl}$ : confidence interval; ECRHS: European Community Respiratory Health Survey. ${ }^{\#}$ : adjusted for age, height, weight, sex, pack-years, previous and current smoking; ๆ: forced VC in the Rotterdam and ECRHS studies, or inspiratory VC in the Vlagtwedde-Vlaardingen study.
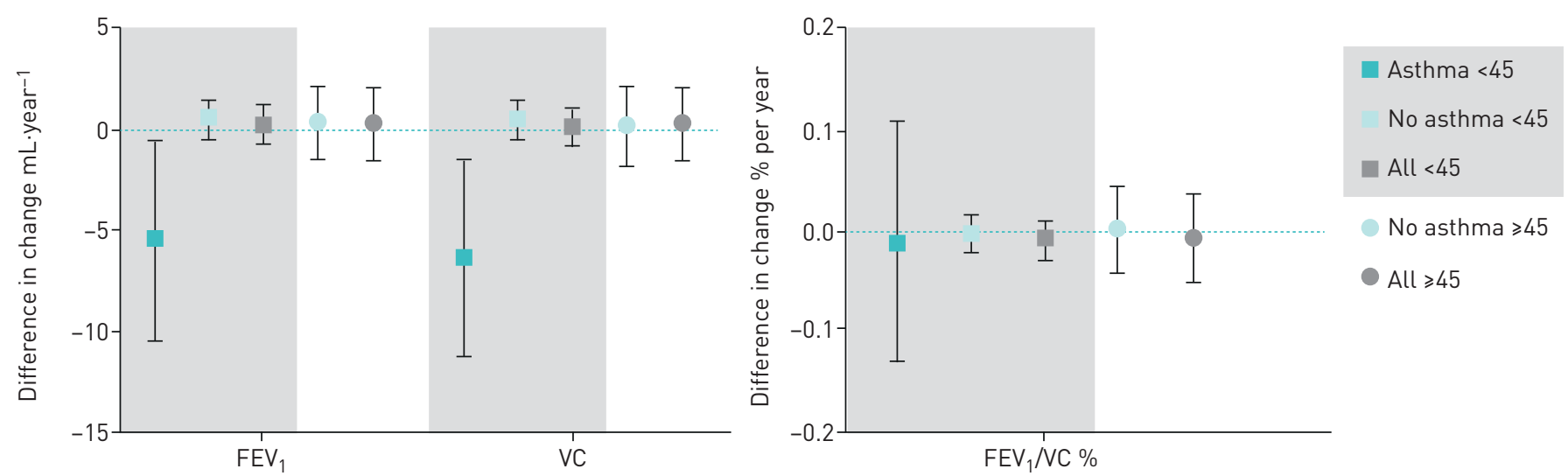

FIGURE 3 Longitudinal meta-analyses, presenting results for the whole cohort and stratified for asthma. Grey-shaded areas represent the meta-estimates and $95 \%$ confidence intervals for the two <45 years cohorts. FEV 1 : forced expiratory volume in $1 \mathrm{~s}$; VC: vital capacity (forced VC in the Rotterdam and European Community Respiratory Health Survey studies, or inspiratory VC in the Vlagtwedde-Vlaardingen study). 


\section{TABLE 4 Associations between elevated blood eosinophils $\left(\geqslant 300\right.$ cells $\left.\mu \mathrm{L}^{-1}\right)$ and excess lung function decline over time}

\begin{tabular}{|c|c|c|c|}
\hline & $\begin{array}{c}\text { FEV }_{1} \text { adjusted }^{\#} \mathrm{~mL} \cdot \text { year }^{-1} \\
\beta(95 \% \mathrm{CI})\end{array}$ & $\begin{array}{l}\text { VC adjusted } \\
\beta(95 \% \mathrm{CI})\end{array}$ & 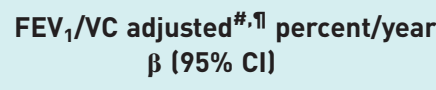 \\
\hline $\begin{array}{l}\text { Vlagtwedde-Vlaardingen }<45 \text { years of } \\
\text { age, } n=2909\end{array}$ & $0.6(-0.4$ to 1.5$)$ & $0.4(-0.5$ to 1.4$)$ & $-5.7 \times 10^{-3}\left(-2.5 \times 10^{-2}\right.$ to $\left.1.3 \times 10^{-2}\right)$ \\
\hline ECRHS-Uppsala, $n=487$ & $-6.4(-10.5$ to -2.3$)$ & $-7.2(-11.9$ to -2.4$)$ & $-3.4 \times 10^{-2}\left(-1.1 \times 10^{-1}\right.$ to $\left.4.2 \times 10^{-2}\right)$ \\
\hline $\begin{array}{l}\text { Vlagtwedde-Vlaardingen } \geqslant 45 \text { years of } \\
\text { age, } n=737\end{array}$ & $0.3(-1.4$ to 2.1$)$ & $0.3(-1.6$ to 2.1$)$ & $-3.4 \times 10^{-3}\left(-4.7 \times 10^{-2}\right.$ to $\left.4.0 \times 10^{-2}\right)$ \\
\hline
\end{tabular}

account for some of the associations found in the older cohort. However, we tried to account for this by adjusting for age.

In the longitudinal analyses, only the ECRHS-Uppsala cohort showed an accelerated lung function decline among the participants with elevated blood eosinophils. The ECRHS-Uppsala cohort had a prevalence of $14 \%$ asthmatic individuals who contributed to the longitudinal analysis due to enrichment with subjects with respiratory symptoms, according to the ECRHS protocol. Asthma is associated with both higher blood eosinophil levels and an accelerated lung function decline. Indeed, in the stratified analysis for asthma, the significant association between an elevated blood eosinophil level and an accelerated $\mathrm{FEV}_{1}$ decline was only present among the asthmatic individuals in the ECRHS-Uppsala cohort. Also in the $<45$ years Vlagtwedde-Vlaardingen cohort, elevated blood eosinophil levels were associated with an accelerated VC decline among asthmatic individuals, but not among non-asthmatic individuals. Surprisingly, no association was seen between elevated blood eosinophils and lower lung function among the asthmatic individuals in the ECRHS or the Rotterdam cohorts in the cross-sectional analyses, possibly a consequence of availability of better treatments for inflammation in this era with greater access to ICS.

Earlier studies were inconclusive. In a 20-year study of young adults, HANCox et al. [18] found higher blood eosinophil levels to be associated with lower $\mathrm{FEV}_{1}$ and $\mathrm{FEV}_{1} / \mathrm{FVC}$, but not with a lower FVC. These associations were found in both asthmatic and non-asthmatic individuals. However, other investigations

TABLE 5 Asthma-stratified analysis, associations between elevated blood eosinophils $\left(\geqslant 300\right.$ cells $\left.\mu \mathrm{L}^{-1}\right)$ and excess lung

function decline over time

\begin{tabular}{|c|c|c|c|}
\hline & $\begin{array}{c}\text { FEV }_{1} \text { adjusted }^{\#} \mathrm{~mL}^{-y_{e a r}}{ }^{-1} \\
\beta(95 \% \mathrm{CI})\end{array}$ & $\begin{array}{c}\text { VC adjusted }{ }^{\#, \uparrow} \mathrm{mL}^{-y_{e a r}}{ }^{-1} \\
\beta(95 \% \mathrm{CI})\end{array}$ & $\begin{array}{c}\text { FEV }_{1} / \text { VC adjusted } \\
\text { B }(95 \% \text { CI) }\end{array}$ \\
\hline $\begin{array}{l}\text { Asthma } \\
\text { Vlagtwedde-Vlaardingen }<45 \text { years of } \\
\text { age, } n=109\end{array}$ & $-3.8(-9.4$ to 1.9$)$ & $-5.8(-11.2$ to -0.4$)$ & $2.2 \times 10^{-2}\left(-1.3 \times 10^{-1}\right.$ to $\left.1.7 \times 10^{-1}\right)$ \\
\hline $\begin{array}{l}\text { No asthma } \\
\text { Vlagtwedde-Vlaardingen }<45 \text { years of } \\
\text { age, } n=2797\end{array}$ & $0.8(-0.2$ to 1.8$)$ & $0.7(-0.2$ to 1.7$)$ & $-3.3 \times 10^{-3}\left(-2.2 \times 10^{-2}\right.$ to $\left.1.6 \times 10^{-2}\right)$ \\
\hline $\begin{array}{l}\text { No asthma } \\
\text { ECRHS-Uppsala, } n=416\end{array}$ & $-4.0(-8.5$ to 0.5$)$ & $-6.1(-11.8$ to -0.5$)$ & $2.3 \times 10^{-2}\left(-5.5 \times 10^{-2}\right.$ to $\left.1.0 \times 10^{-1}\right)$ \\
\hline $\begin{array}{l}\text { Asthma } \\
\text { Vlagtwedde-Vlaardingen } \geqslant 45 \text { years of } \\
\text { age, } n=19\end{array}$ & Too few & Too few & Too few \\
\hline \multicolumn{4}{|c|}{$\begin{array}{l}\text { Significant associations in bold. } \mathrm{FEV}_{1} \text { : forced expiratory volume in } 1 \mathrm{~s} ; \mathrm{VC} \text { : vital capacity; } \beta \text { : regression coefficient; } \mathrm{Cl} \text { : confidence interval } \\
\text { ECRHS: European Community Respiratory Health Survey. ": adjusted for age, height, weight, sex, pack-years, all in interaction with time } \\
\text { १: forced VC in the Rotterdam and ECRHS studies, or inspiratory VC in the Vlagtwedde-Vlaardingen study. }\end{array}$} \\
\hline
\end{tabular}


have not found a clear association between higher blood eosinophil levels and accelerated $\mathrm{FEV}_{1}$ decline $[19,20]$ or even a slower decline $[21,22]$. This is in contrast to the findings in this investigation, where the accelerated lung function decline was mainly seen in asthmatic individuals with elevated blood eosinophils, and there was also an effect on the VC.

A strength of this investigation is the inclusion of four large cohorts with both young and old individuals with and without asthma. For three of the cohorts, we also had follow-up measurements with a follow-up time of up to 25 years. Interestingly, when analysed with the same method, we found a fairly similar association between blood eosinophils and lung function in the cohorts analysed cross-sectionally in the respective age strata, despite differences in composition, time frame and exposures. However, when stratified for asthma, the associations were heterogeneous. One explanation could be the differences in asthma diagnosis between Vlagtwedde-Vlaardingen, ECRHS-Uppsala and Rotterdam. Another important difference is the use of ICS in both the ECRHS-Uppsala and Rotterdam cohorts, but not in the Vlagtwedde-Vlaardingen cohorts, which were followed up before ICS were commonly used, although some patients might have received systemic treatment with corticosteroids. Hence, better treatment of inflammation in the two later studies (ECRHS-Uppsala and Rotterdam) could be the reason for the better lung function measures among the asthmatic individuals with elevated blood eosinophils in these cohorts in the cross-sectional analyses. Interestingly, despite this, the $<45$ years old cohorts had an accelerated lung function decline among asthmatic individuals with elevated blood eosinophil levels, compared with asthmatic individuals with normal blood eosinophil levels, with the largest decline in the ECRHS-Uppsala cohort. In other words, we did not find a reduced lung function decline despite ICS use in about $36 \%$ of the participants with asthma in the ECRHS-Uppsala cohort, as compared to the Vlagtwedde-Vlaardingen cohort with no ICS use. However, the accelerated decline in VC also among non-asthmatic individuals with elevated blood eosinophil levels in the ECRHS-Uppsala cohort suggests that this association is not limited to persons with asthma.

There are some limitations to our study. The blood eosinophil measurements were taken only at one time-point, but it is known that blood eosinophils vary over time [34]. Further, only pre-bronchodilator lung function was measured. In subjects with asthma, a low pre-bronchodilator $\mathrm{FEV}_{1}$ could be a sign of uncontrolled disease and undertreatment associated with temporarily higher blood eosinophil levels. This would possibly lead to large fluctuations in lung function measurements between the visits. However, the long follow-up time should to some degree attenuate for the effect of temporal fluctuations. The cohorts were also followed during different decades and in different countries (Vlagtwedde-Vlaardingen and Rotterdam studies in the Netherlands and ECRHS-Uppsala in Sweden) with different exposures to environmental factors that could possibly affect the results. The definitions of asthma and lung function measures (FVC and IVC) varied among the studies and are further limitations.

In conclusion, this study observed an association between elevated blood eosinophil levels and lower lung function cross-sectionally. Moreover, elevated blood eosinophils in the younger cohorts were associated with an overall lower lung function, while in the older cohorts an association with an obstructive pattern was mainly found. We could not consistently show an accelerated lung function decline related to elevated blood eosinophil levels, and our stratified analyses for asthma suggested that the association between elevated blood eosinophils and an accelerated $\mathrm{FEV}_{1}$ decline is generally present in asthmatic individuals, but not in the general population.

Conflict of interest: I. Mogensen has nothing to disclose. J.M. Vonk has nothing to disclose. S.R.A. Wijnant reports an award from GlaxoSmithKline outside the submitted work. X. Zhou has no conflicts of interest to declare. H.M. Boezen has nothing to disclose. G. Brusselle has nothing to disclose. L. Lahousse reports awards sponsored by AstraZeneca and Chiesi, and expert consultation for Boehringer Ingelheim GmbH and Novartis, outside the submitted work. C. Janson has nothing to disclose. A. Malinovschi has nothing to disclose.

Support statement: The current work was funded by the U-4 Network, the Swedish Heart and Lung Foundation, Konsul Berghs Foundation, Bror Hjerpstedts stiftelse, Uppsala University, and the Swedish Asthma and Allergy Foundation. Funding information for this article has been deposited with the Crossref Funder Registry.

\section{References}

1 Wang X, Mensinga TT, Schouten JP, et al. Determinants of maximally attained level of pulmonary function. Am J Respir Crit Care Med 2004; 169: 941-949.

2 Postma DS, Bush A, van den Berge M. Risk factors and early origins of chronic obstructive pulmonary disease. Lancet 2015; 385: 899-909.

3 Agusti A, Faner R. Lung function trajectories in health and disease. Lancet Respir Med 2019; 7: 358-364.

4 Wijnant SRA, De Roos E, Kavousi M, et al. Trajectory and mortality of preserved ratio impaired spirometry: the Rotterdam Study. Eur Respir J 2020; 55: 1901217. 
Eisner MD, Anthonisen N, Coultas D, et al. An official American Thoracic Society public policy statement: Novel risk factors and the global burden of chronic obstructive pulmonary disease. Am J Respir Crit Care Med 2010; 182: 693-718.

6 Mauad T, Bel EH, Sterk PJ. Asthma therapy and airway remodeling. J Allergy Clin Immunol 2007; 120: 997-1009. quiz 1010-1001.

7 Nishimura M, Makita $\mathrm{H}$, Nagai $\mathrm{K}$, et al. Annual change in pulmonary function and clinical phenotype in chronic obstructive pulmonary disease. Am J Respir Crit Care Med 2012; 185: 44-52.

8 Singh D, Kolsum U, Brightling CE, et al. Eosinophilic inflammation in COPD: prevalence and clinical characteristics. Eur Respir J 2014; 44: 1697-1700.

9 Shin SH, Park HY, Kang D, et al. Serial blood eosinophils and clinical outcome in patients with chronic obstructive pulmonary disease. Respir Res 2018; 19: 134.

10 Schleich FN, Chevremont A, Paulus V, et al. Importance of concomitant local and systemic eosinophilia in uncontrolled asthma. Eur Respir J 2014; 44: 97-108.

11 Schleich FN, Manise M, Sele J, et al. Distribution of sputum cellular phenotype in a large asthma cohort: predicting factors for eosinophilic vs neutrophilic inflammation. BMC Pulm Med 2013; 13: 11.

12 Pignatti P, Visca D, Cherubino F, et al. Do blood eosinophils strictly reflect airway inflammation in COPD? Comparison with asthmatic patients. Respir Res 2019; 20: 145-145.

13 Pavord ID, Korn S, Howarth P, et al. Mepolizumab for severe eosinophilic asthma (DREAM): a multicentre, double-blind, placebo-controlled trial. Lancet 2012; 380: 651-659.

14 Shapira U, Krubiner M, Ehrenwald M, et al. Eosinophil levels predict lung function deterioration in apparently healthy individuals. Int J Chron Obstruct Pulmon Dis 2019; 14: 597-603.

15 Lewis SA, Pavord ID, Stringer JR, et al. The relation between peripheral blood leukocyte counts and respiratory symptoms, atopy, lung function, and airway responsiveness in adults. Chest 2001; 119: 105-114.

16 Ulrik CS. Eosinophils and pulmonary function: an epidemiologic study of adolescents and young adults. Ann Allergy Asthma Immunol 1998; 80: 487-493.

17 Mogensen I, Alving K, Jacinto T, et al. Simultaneously elevated FeNO and blood eosinophils relate to asthma morbidity in asthmatics from NHANES 2007-12. Clin Exp Allergy 2018; 48: 935-943.

18 Hancox RJ, Pavord ID, Sears MR. Associations between blood eosinophils and decline in lung function among adults with and without asthma. Eur Respir J 2018; 51: 1702536.

19 Frette C, Annesi I, Korobaeff M, et al. Blood eosinophilia and FEV1. Cross-sectional and longitudinal analyses. Am Rev Respir Dis 1991; 143: 987-992.

20 Nadif R, Siroux V, Boudier A, et al. Blood granulocyte patterns as predictors of asthma phenotypes in adults from the EGEA study. Eur Respir J 2016; 48: 1040-1051.

21 Ulrik CS, Backer V, Dirksen A. A 10 year follow up of 180 adults with bronchial asthma: factors important for the decline in lung function. Thorax 1992; 47: 14-18.

22 Semprini R, Williams M, Semprini A, et al. Type 2 biomarkers and prediction of future exacerbations and lung function decline in adult asthma. J Allergy Clin Immunol Pract 2018; 6: 1982-1988. e1981.

23 van der Lende R, Kok T, Peset R, et al. Longterm exposure to air pollution and decline in VC and FEV1. Recent results from a longitudinal epidemiologic study in the Netherlands. Chest 1981; 80: Suppl. 1, 23-26.

24 van Diemen CC, Postma DS, Vonk JM, et al. A disintegrin and metalloprotease 33 polymorphisms and lung function decline in the general population. Am J Respir Crit Care Med 2005; 172: 329-333.

25 Norback D, Bjornsson E, Janson C, et al. Current asthma and biochemical signs of inflammation in relation to building dampness in dwellings. Int J Tuberc Lung Dis 1999; 3: 368-376.

26 Ikram MA, Brusselle GGO, Murad SD, et al. The Rotterdam Study: 2018 update on objectives, design and main results. Eur J Epidemiol 2017; 32: 807-850.

27 de Roos EW, Lahousse L, Verhamme KMC, et al. Asthma and its comorbidities in middle-aged and older adults; the Rotterdam Study. Respir Med 2018; 139: 6-12.

28 Quanjer PH, Stanojevic S, Cole TJ, et al. Multi-ethnic reference values for spirometry for the 3-95-yr age range: the global lung function 2012 equations. Eur Respir J 2012; 40: 1324-1343.

29 Hospers JJ, Schouten JP, Weiss ST, et al. Asthma attacks with eosinophilia predict mortality from chronic obstructive pulmonary disease in a general population sample. Am J Respir Crit Care Med 1999; 160: 1869-1874

30 Simmons A, Leaverton P, Elbert G. Normal laboratory values for differential white cell counts established by manual and automated cytochemical methods (Hemalog D-TM). J Clin Pathol 1974; 27: 55-58.

31 Glindmeyer HW, Lefante JJ, McColloster C, et al. Blue-collar normative spirometric values for Caucasian and African-American men and women aged 18 to 65. Am J Respir Crit Care Med 1995; 151: 2 Pt. 1, 412-422.

32 Burrows $\mathrm{B}$, Lebowitz MD, Camilli $\mathrm{AE}$, et al. Longitudinal changes in forced expiratory volume in one second in adults. Methodologic considerations and findings in healthy nonsmokers. Am Rev Respir Dis 1986; 133: 974-980.

33 Jacinto T, Malinovschi A, Janson C, et al. Evolution of exhaled nitric oxide levels throughout development and aging of healthy humans. J Breath Res 2015; 9: 036005.

34 Coumou $\mathrm{H}$, Westerhof GA, de Nijs SB, et al. Diagnosing persistent blood eosinophilia in asthma with single blood eosinophil or exhaled nitric oxide level. Respir Med 2018; 141: 81-86. 